\title{
Factors associated with prevalence of pain and musculoskeletal injuries in Brazilian kickboxers: a cross-sectional study
}

\author{
Glauko André Figueiredo Dantas ${ }^{1}$, Clarissa Lula de Menezes Cruz $^{2}$, Flávio Santos Silva ${ }^{3}$, \\ Mikhail Santos Cerqueira ${ }^{2}$, Bento João Abreu${ }^{4}$, Wouber Hérickson Brito Vieira ${ }^{2}$ \\ 1 Physical Therapy Department, Federal University of São Carlos; ${ }^{2}$ Department of Physical Therapy, Federal University \\ of Rio Grande do Norte (UFRN); ${ }^{3}$ Department of Health Sciences, Federal University of the Semiarid Region, Mossoró, \\ Brazil; 4 Morphology Department, Federal University of Rio Grande do Norte; Natal, Brazil
}

\section{Summary}

Study aim: The purpose of this study was to determine the prevalence and factors associated with pain and musculoskeletal injuries in Brazilian kickboxers.

Material and methods: This is a cross-sectional study composed of a population of kickboxers from the academies affiliated to the Rio Grande do Norte State Federation of Kickboxing. The study was conducted by means of a questionnaire regarding their demographic data, graduation and level of participation in the modality, routines of procedures during training, and pain/ discomfort regions and respective intensities. In addition, the characteristics, types, and regions of the injuries were evaluated. Results: Of the 132 kickboxers included, a high prevalence of pain $(84.09 \%)$ was observed and associated with the female gen$\operatorname{der}(\mathrm{OR}=3.62$; CI95\% 1.29-10.13) and body mass index (OR = 0.80; CI95\% 0.71-0.91). In addition, the kickboxers presented a moderate percentage of injuries $(40.91 \%)$ that were associated with longer training time $(\mathrm{OR}=5.82 ; \mathrm{CI} 95 \% 2.68-12.61)$ and contact level in the training sessions $(\mathrm{OR}=3.53$; CI95\% 1.85-6.72).

Conclusions: There was a high prevalence of musculoskeletal pain in kickboxers, mainly associated with female gender and with lower body mass. Musculoskeletal injuries were moderately prevalent in kickboxers who trained more than one hour per session and with an intense contact level.

Keywords: Epidemiology - Athletic performance - Overuse injury - Kickboxing injury

\section{Introduction}

Kickboxing is a combat sport in which two opponents perform powerful strokes with the hands, elbows, knees, legs, and feet on any target on the opponent's body except the groin [5, 18]. Kickboxing competitions have three to twelve rounds, each lasting between two and four minutes $[2,17]$. Kickboxers are subjected to high physical and physiological demands due to the large number of actions performed during a fight [3].

The number of adepts practicing kickboxing and other martial arts modalities is growing as these modalities provide individual protection [15], aerobic and anaerobic conditioning [18], and are widely offered in gyms and recreation centers [6]. In addition, martial arts can be considered an excellent therapeutic tool, contributing to the development of concentration, socialization, self-esteem, and discipline [7].
Despite the benefits of kickboxing practice, pain and injuries can arise from the use of punches and kicks [14, 21], as well as the need to develop strength and agility in extreme contact situations. The scarce data available on the prevalence and incidence of kickboxer injuries indicate that the most affected regions are the head, arms, trunk, knees, and ankles $[15,16,18,21]$. In this context, besides the characteristics of the modality, factors such as conditioning and physical profile, level of experience and technical skill of the athlete, and intensity and amount of weekly training may be associated with a high risk of injuries in kickboxers [2, 18].

The prevalence of kickboxer injuries has been described in the United Kingdom [5], United States [15], Australia [21], and Thailand [19]. However, no studies were found evaluating the pain profile and musculoskeletal injuries in Brazilian kickboxers. Besides that, previous studies analyzed samples at gyms or events, leaving out injured athletes [5], while other studies did not evaluate possible causes of the most common types of injuries 
[15] or did not assess the most common injury mechanism [21]. Additionally, factors associated with the prevalence of pain and musculoskeletal injuries in kickboxers have not been evaluated in the literature.

As the identification of factors associated with the injury profile can be useful for developing injury prevention programs and improving performance, this study aimed to determine the prevalence and factors associated with pain and musculoskeletal injuries in Brazilian kickboxers.

\section{Materials and methods}

\section{Study design, participants and eligibility criteria}

This was a cross-sectional descriptive study, in which the kickboxer population (all practitioners) of academies affiliated with the State Kickboxing Federation of Rio Grande do Norte was recruited.

The inclusion criteria were as follows: at least 1 month of practice time; training regularly at least twice a week; and training at a gym affiliated with the State Kickboxing Federation. The exclusion criteria were as follows: refusing to voluntarily respond to the proposed evaluation questionnaires or ceasing the training routine. Informed written consent was obtained from each eligible participant. The study was approved by the Human Research Ethics Committee of the Universidade Federal do Rio Grande do Norte (REC/UFRN 122.053) and conducted according to the Declaration of Helsinki guidelines.

\section{General procedures}

Initially, the owners of the academies were consulted about the possibility of conducting the research. Data acquisition was performed in a 3-month period by researchers previously trained to standardize the interview following a sequence of questions and clarify any doubts raised by the athletes.

A questionnaire adapted to evaluate the characteristics of the injuries was applied [5]. The questions addressed demographic data of the participants, classification of the athletes regarding graduation and level of participation, routine of procedures during training, and characteristics, types, and regions of injuries. The sites and intensity of pain/discomfort were assessed using an adapted questionnaire [20]. This questionnaire presents a diagram with a description of the body regions for identification of pain/ musculoskeletal discomfort sites. We considered an injury as any pain or dysfunction that limited or removed the athlete from training and/or competitions for at least one scheduled match or team training session [10].

A theoretical model based on proximal and distal factors was constructed to analyze the possible associations between demographic or training-related aspects and the presence of musculoskeletal pain and lesions. The independent variables were divided into four hierarchical blocks: block 1 composed of demographic characteristics; block 2 composed of factors related to the classification of kickboxing athletes; block 3 composed of aspects related to the training of kickboxers; block 4 considering pretraining aspects (Fig. 1).

$$
\begin{aligned}
& \text { Demographic characteristics } \\
& \text { - Gender } \\
& \text { - Age } \\
& \text { - Body Mass Index } \\
& \text { Athlete's classification } \\
& \text { - Graduation } \\
& \text { - Athlete level } \\
& \text { Training-related factors } \\
& \text { - Training time } \\
& \text { - No. of training sessions } \\
& \text { - Duration of training } \\
& \text { - Contact level } \\
& \text { Pre-training-related factors } \\
& \text { - Warm up } \\
& \text { - Worm-up time } \\
& \text { - Stretching } \\
& \text { - Stretching time }
\end{aligned}
$$

\section{Distal factors}

\section{Proximal factors}

Fig. 1. Theoretical model for investigation of factors associated with presence of pain and musculoskeletal injuries in kickboxers, divided into hierarchical blocks

\section{Statistical analysis}

As a first approach, descriptive statistics were analyzed for all variables in the study. The quantitative variables are expressed as measures of central tendency and dispersion. The categorical variables are expressed as absolute and relative frequency.

Differences in the independent variables with respect to the presence or absence of pain and injury were detected by the chi-square test (categorical variables) and independent t-test or Mann-Whitney test (quantitative variables), according to the normality of the distribution. The variables that presented $\mathrm{p}<0.20$ were included in the multivariate analysis and then a logistic regression model was constructed to determine which factors were associated with the presence of pain and injury. The odds ratios (OR) were presented considering a significance level of 5\% and a 95\% confidence interval. All statistical analysis was performed using SPSS version 20.0 (IBM Corp., Armonk, NY, USA).

\section{Results}

Of the 132 recruited kickboxing practitioners, a high prevalence of pain $(84.09 \%$; 95\% CI, 77.77-90.41) was 
observed, and the main site affected was the legs (64.39\%) with an average intensity of pain of $4.2 \pm 1.85$. Figures 2 and 3 present, respectively, the data related to the main pain sites and their intensities.

A moderate percentage of injuries $(40.91 \%$; $95 \%$ CI, 32.41-49.41) resulted from kickboxing with a median of $3 \pm 3$ injuries per athlete. These injuries resulted in an average absence of $33.74 \pm 80.19$ days. The majority of the 129 registered injuries occurred during training.
The most prevalent type, mechanism, and location of injury was contusion through direct leg trauma (Table 1).

Pain had a significant association with being male $(p<0.022)$, age $(p<0.044)$, and having a lower body mass $(\mathrm{p}<0.005)$.

The presence of injuries demonstrated a significant association with being male, being taller, longer experience of training time, being amateur, training with a level of

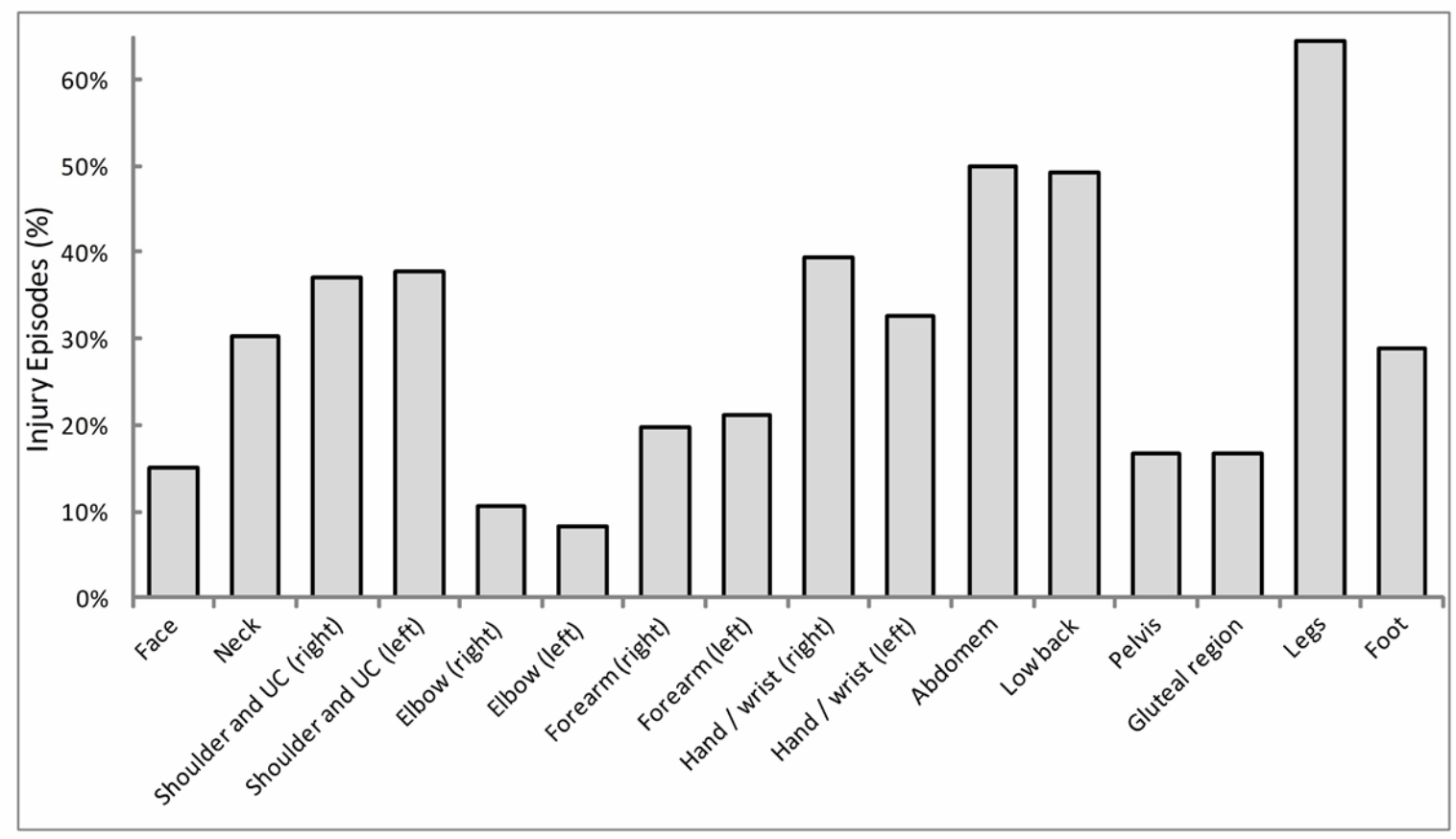

Fig. 2. Regions of the body affected by pain from kickboxing practice

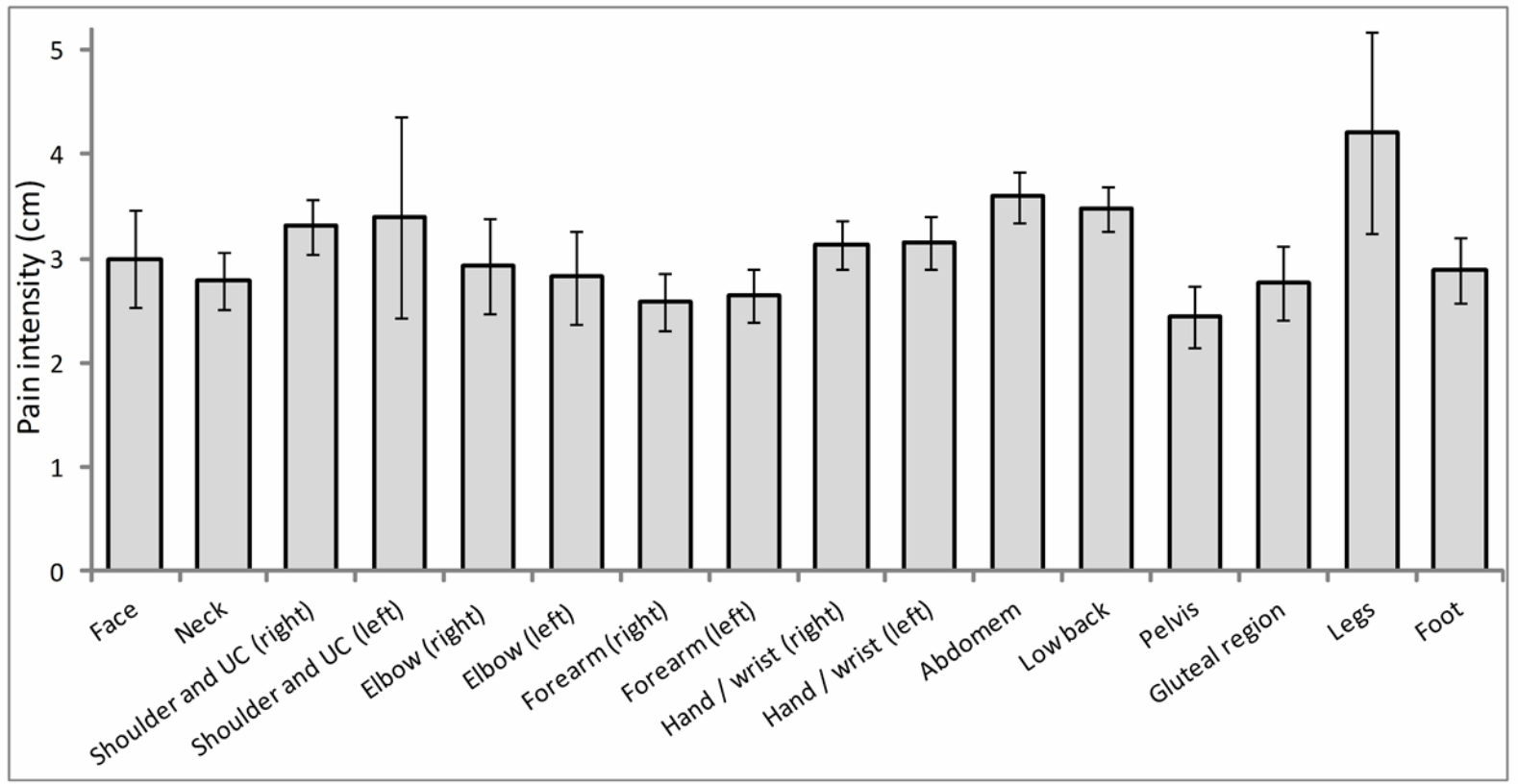

Fig. 3. Intensity of pain from kickboxing practice 
Table 1. Characteristics of injuries resulting from kickboxing

\begin{tabular}{|c|c|c|c|}
\hline & & Absolute frequency & Relative frequency [\%] \\
\hline \multirow{3}{*}{ Injury } & No & 78 & 59.09 \\
\hline & & & \\
\hline & Yes & 54 & 40.91 \\
\hline \multirow{3}{*}{ Injury occasion } & Training & 119 & 92.60 \\
\hline & Sports event & 3 & 1.85 \\
\hline & Both & 7 & 5.55 \\
\hline \multirow{8}{*}{ Location of injury } & Thigh/Knee/Shank & 46 & 35.70 \\
\hline & Ankle/Foot & 18 & 13.95 \\
\hline & Wrist/Hand & 18 & 13.95 \\
\hline & Shoulder/Pectoral & 13 & 10.10 \\
\hline & Face & 13 & 10.10 \\
\hline & Arm/Elbow/Forearm & 11 & 8.50 \\
\hline & Abdomem & 8 & 6.20 \\
\hline & Low back/Pelvis & 2 & 1.50 \\
\hline \multirow{10}{*}{ Type of injury } & Contusion & 34 & 26.40 \\
\hline & Sprain & 25 & 19.40 \\
\hline & Excoriation & 20 & 15.50 \\
\hline & Strain & 18 & 14.00 \\
\hline & Luxation & 13 & 10.10 \\
\hline & Fracture & 7 & 5.40 \\
\hline & Epistaxis & 5 & 3.90 \\
\hline & Muscle rupture & 3 & 2.30 \\
\hline & Ligament rupture & 3 & 2.30 \\
\hline & Laceration & 1 & 0.80 \\
\hline \multirow{3}{*}{ Mechanism of injury } & Direct trauma & 47 & 36.43 \\
\hline & Microtrauma repetition & 43 & 33.33 \\
\hline & Inappropriate sporting gesture & 39 & 30.24 \\
\hline
\end{tabular}

contact considered intense, and performing a longer warmup (Table 2). In addition, there was an association between not having an injury and being female, being a white belt, training for less time, and training with a contact level classified as mild (Table 2 ).

Table 3 presents the variables analyzed in the logistic regression for pain and musculoskeletal injury outcomes. Women were 2.62 times more likely to experience pain from kickboxing. In addition, presenting a BMI of $24 \pm 4$ decreased the probability of experiencing pain by 0.2 times.

Concerning injury, it was observed that duration of training over one hour increased the probability of having an injury by 4.82 times. It was also observed that training with intense contact increased the probability of presenting injury resulting from kickboxing practice by 2.53 times.

\section{Discussion}

This study aimed to determine the prevalence and factors associated with pain and musculoskeletal injuries in Brazilian kickboxers. We identified a high prevalence of pain $(84.09 \%)$, which was mainly associated with gender and BMI, and a moderate prevalence of injuries (40.91\%) in the evaluated kickboxers. Additionally, the presence of injuries was associated with longer training duration and an intense level of contact.

The body regions with a higher prevalence of pain were the legs, abdomen, and lower back. Considering that kickboxing is a combat sport that requires complex skills [18], it is probable that these body regions were the most affected due to high physical demand and the need for trunk stabilization during the kicking movements. 
Table 2. Associations between pain and musculoskeletal injury with demographic characteristics and training-related factors of kickboxers

\begin{tabular}{|c|c|c|c|c|c|c|c|}
\hline & & $\begin{array}{l}\text { With } \\
\text { pain }\end{array}$ & $\begin{array}{l}\text { Without } \\
\text { pain }\end{array}$ & $\mathrm{P}$ value & $\begin{array}{l}\text { With } \\
\text { injury }\end{array}$ & $\begin{array}{l}\text { Without } \\
\text { injury }\end{array}$ & $P$ value \\
\hline \multicolumn{8}{|l|}{ Demographic characteristics } \\
\hline \multirow{2}{*}{ Gender } & Male & $94.45 \%$ & $5.55 \%$ & \multirow{2}{*}{0.022} & 71.29 & 28.71 & \multirow{2}{*}{0.006} \\
\hline & Female & $84.85 \%$ & $15.15 \%$ & & 52.52 & 47.48 & \\
\hline Age (years)* & & $24.00 \pm 7$ & $28.00 \pm 14$ & 0.044 & $25.00 \pm 7$ & $24.00 \pm 11$ & 0.209 \\
\hline Body mass index $\left(\mathrm{kg} / \mathrm{m}^{2}\right)^{*}$ & & $24.00 \pm 4$ & $26.00 \pm 7$ & 0.005 & $24.00 \pm 4$ & $25.00 \pm 5$ & 0.734 \\
\hline \multicolumn{8}{|l|}{ Athlete's classification } \\
\hline \multirow{7}{*}{ Graduation } & White & $84.48 \%$ & $15.52 \%$ & & $39.65 \%$ & $60.35 \%$ & \multirow{7}{*}{0.0001} \\
\hline & Yellow & $96.15 \%$ & $3.85 \%$ & & $80.77 \%$ & $19.23 \%$ & \\
\hline & Green & $100 \%$ & 0 & & $90.00 \%$ & $10.00 \%$ & \\
\hline & Blue & $100 \%$ & 0 & 0.207 & $100 \%$ & 0 & \\
\hline & Red & $90.90 \%$ & $9.10 \%$ & & $90.90 \%$ & $9.10 \%$ & \\
\hline & Brown & $100 \%$ & 0 & & $100 \%$ & 0 & \\
\hline & Black & $100 \%$ & 0 & & $100 \%$ & 0 & \\
\hline \multirow{3}{*}{ Athlete level } & Beginner & $89.35 \%$ & $10.65 \%$ & & $59.17 \%$ & $40.83 \%$ & \multirow{3}{*}{0.049} \\
\hline & Amateur & $92.10 \%$ & $7.90 \%$ & 0.772 & $76.31 \%$ & $23.69 \%$ & \\
\hline & Professional & 0 & 0 & & 0 & 0 & \\
\hline \multicolumn{8}{|l|}{ Training-related factors } \\
\hline \multirow{2}{*}{ Training time } & Up to 1 year & $89.92 \%$ & $10.08 \%$ & \multirow{2}{*}{0.967} & $47.28 \%$ & $52.72 \%$ & \multirow{2}{*}{0.0001} \\
\hline & $>1$ year & $89.75 \%$ & $10.25 \%$ & & $87.17 \%$ & $12.83 \%$ & \\
\hline No. of training sessions (per week)* & & $3 \pm 2$ & $3 \pm 0$ & 0.622 & $3 \pm 2$ & $3 \pm 2$ & 0.848 \\
\hline Duration of training & $\begin{array}{l}\text { Up to } 1 \text { hour } \\
>1 \text { hour }\end{array}$ & $\begin{array}{l}86.65 \% \\
95.85 \%\end{array}$ & $\begin{array}{c}13.35 \% \\
4.15 \%\end{array}$ & 0.051 & $\begin{array}{l}57.78 \% \\
70.83 \%\end{array}$ & $\begin{array}{l}42.22 \% \\
29.17 \%\end{array}$ & 0.065 \\
\hline Contact Level & $\begin{array}{l}\text { Absent } \\
\text { Light } \\
\text { Intense } \\
\text { Competition }\end{array}$ & $\begin{array}{c}0 \\
91.11 \% \\
88.88 \% \\
0\end{array}$ & $\begin{array}{c}0 \\
8.89 \% \\
11.12 \% \\
0\end{array}$ & 0.600 & $\begin{array}{c}0 \\
42.22 \% \\
77.77 \% \\
0\end{array}$ & $\begin{array}{c}0 \\
57.77 \% \\
22.23 \% \\
0\end{array}$ & 0.0001 \\
\hline \multicolumn{8}{|l|}{ Pre-Training-related factors } \\
\hline Warm-up & $\begin{array}{l}\text { Yes } \\
\text { No }\end{array}$ & $\begin{array}{c}89.34 \% \\
100 \%\end{array}$ & $\begin{array}{c}10.66 \% \\
0\end{array}$ & 0.603 & $\begin{array}{l}61.43 \% \\
80.00 \%\end{array}$ & $\begin{array}{l}38.57 \% \\
20.00 \%\end{array}$ & 0.326 \\
\hline Warm-up time (minutes)* & & $20 \pm 15$ & $15 \pm 15$ & 0.562 & $20 \pm 15$ & $15 \pm 16$ & 0.008 \\
\hline Stretching & $\begin{array}{l}\text { Yes } \\
\text { No }\end{array}$ & $\begin{array}{l}89.82 \% \\
90.00 \%\end{array}$ & $\begin{array}{l}10.18 \% \\
10.00 \%\end{array}$ & 0.973 & $\begin{array}{l}63.47 \% \\
57.50 \%\end{array}$ & $\begin{array}{l}36.53 \% \\
42.50 \%\end{array}$ & 0.484 \\
\hline Stretching time (minutes)* & & $5 \pm 8$ & $5 \pm 9$ & 0.468 & $5 \pm 9$ & $5 \pm 8$ & 0.863 \\
\hline
\end{tabular}

Legend: * - Mann-Whitney test.

To the best of our knowledge, no previous study has evaluated pain in kickboxers and the association of pain with gender, age, and body mass is quite controversial. Some studies with healthy subjects have shown that women are more sensitive to pain than men, while others did not identify significant differences between the genders [13]. Ostrum et al. [15] found that pain thresholds increased with age in various stimulus modalities, revealing 
Table 3. Final logistic regression model for pain and musculoskeletal injury outcomes

\begin{tabular}{|c|c|c|c|c|c|}
\hline & & \multicolumn{2}{|c|}{ Pain } & \multicolumn{2}{|c|}{ Musculoskeletal injury } \\
\hline & & OR & CI & OR & $\mathrm{CI}$ \\
\hline \multirow{2}{*}{ Gender } & Male & \multicolumn{2}{|c|}{1} & \multicolumn{2}{|c|}{1} \\
\hline & Female & 3.62 & $1.29-10.13$ & 1.43 & $0.74-2.76$ \\
\hline Age & & 0.96 & $0.90-1.02$ & - & - \\
\hline Body mass index & & 0.80 & $0.71-0.91$ & - & - \\
\hline \multirow{2}{*}{ Graduation } & & - & - & \multicolumn{2}{|c|}{1} \\
\hline & & - & - & 0.96 & $0.72-1.28$ \\
\hline \multirow{2}{*}{ Training time } & Up to 1 year & - & - & \multicolumn{2}{|c|}{1} \\
\hline & $>1$ year & - & - & 5.82 & $2.68-12.61$ \\
\hline \multirow{2}{*}{ Training duration } & Up to 1 hour & - & - & \multicolumn{2}{|c|}{1} \\
\hline & $>1$ hour & - & - & 1.70 & $0.82-3.49$ \\
\hline \multirow{2}{*}{ Athlete level } & Beginner & - & - & \multicolumn{2}{|c|}{1} \\
\hline & Amateur & - & - & 0.67 & $0.24-1.88$ \\
\hline \multirow{2}{*}{ Contact level } & Light & - & - & \multicolumn{2}{|c|}{1} \\
\hline & Intense & - & - & 3.53 & $1.85-6.72$ \\
\hline Warm-up time & - & - & - & 1.02 & $0.98-1.05$ \\
\hline
\end{tabular}

age differences in response to thermal and electrical stimuli, while pain tolerance decreased with age [12]. The conditions that lead to the expression of different levels of pain between sex and age are not clear and do not seem to be related to the types of stimulation [4]. Therefore, an interaction between biological, psychological, and sociocultural factors has been suggested [1].

Contusion through direct leg trauma (type, injury site, and mechanism, respectively) was the most prevalent injury in the present study and may be related to features inherent in kickboxing: the search for a direct hit and fight completion. Successful combat requires a greater number of points gained, by kicking and punching, or reaching a technical knockout [17]. Our data corroborate other authors [21] who also observed the leg as the main site of kickboxer injuries. Gartland et al. (2001) [5] demonstrated that injuries to the lower limbs, trunk, and upper limbs are more common in beginners, while amateur athletes report more injuries to the lower limbs and head.

In professional kickboxers, direct trauma to the head has also been reported as a major injury [8]. It is noteworthy that in the present study, the majority of the kickboxers were beginners and amateurs. Possibly, as these athletes were not yet performing more refined movements such as kicks to the head to attain a knockout, there was a greater number of injuries to the lower limbs and not the head. Kickboxing is associated with chronic repetitive cranial trauma that can cause unconsciousness and neurological abnormalities [21]. On the other hand, in a recent study, more than half of Muay Thai kickboxing athletes, above all amateurs, demonstrated a history of suspected concussion [9]. Unfortunately, the concussion index was not assessed in our study. However, it is worth mentioning that a concussion education program must be made available to all kickboxing athletes and coaches [9].

Regarding the factors associated with musculoskeletal injuries, Lystad (2015) [8] demonstrated that professional athletes and kickboxers defeated in competitions were 2.5 and 3.5 times, respectively, more susceptible to injuries. Our results indicate that longer and more intense training sessions were associated with the presence of injury. Despite not evaluating the presence of pain or injury, Orhan et al. (2019) [11] showed that most kickboxers train between 60 and 90 minutes (36.2\%) or between 90 and 120 minutes $(25.5 \%)$. Longer training sessions may be associated with overload of the musculoskeletal system. In addition, amateur and beginner athletes may be more exposed to injury due to a high level of contact during training (trying to improve performance and participate in competitions) and lack of mastery of the technique. 
This was the first study to analyze variables intrinsically related to training and associations with the presence of pain and musculoskeletal injuries in kickboxing practitioners. It is also important to note that although data are available on strength performance of Brazilian kickboxers [18], the prevalence of injuries and factors associated with pain and musculoskeletal injuries had not yet been addressed.

The main limitation of this study is that is a cross-sectional study and, as such, a causal relationship cannot be inferred. Therefore, the results should be interpreted with caution.

\section{Conclusion}

In summary, kickboxers present a high prevalence of pain that is mainly associated with the female gender and lower body mass. Furthermore, musculoskeletal injuries are moderately prevalent and associated with training sessions lasting more than 1 hour and an intense contact level.

\section{Conflict of interest: Authors state no conflict of interest.}

\section{References}

1. Bartley E.J., Fillingim R.B. (2013) Sex differences in pain: a brief review of clinical and experimental findings. Br. J. Anaesth., 111: 52-58. Available from: http://www. ncbi.nlm.nih.gov/pubmed/23794645

2. Buse G.J. (2009) Kickboxing. In: R Kordi et al. Combat Sports Medicine. London: Springer-Verlag, 331-351. DOI: 10.1007/978-1-84800-354-5 19.

3. Crisafulli A., Vitelli S., Cappai I., Milia R., Tocco F., Melis F., Concu A. (2009) Physiological responses and energy cost during a simulation of a Muay Thai boxing match. Appl. Physiol. Nutr. Metab., 34: 143-150. Available from: http://www.ncbi.nlm.nih.gov/pubmed/19370044.

4. Fillingim R.B., King C.D., Ribeiro-Dasilva M.C., RahimWilliams B., Riley J.L. (2009) Sex, Gender, and Pain: A Review of Recent Clinical and Experimental Findings. J. Pain, 10: 447-485. Available from: http://www.ncbi. nlm.nih.gov/pubmed/19411059.

5. Gartland S., Malik M.H.A., Lovell M.E. (2001) Injury and injury rates in Muay Thai kick boxing Injury and injury rates in Muay Thai kick boxing United Kingdom and a Muay Thai gala in. 308-313.

6. Jackson K., Edginton-Bigelow K., Bowsheir C., Weston M., Grant E. (2012) Feasibility and effects of a group kickboxing program for individuals with multiple sclerosis: A pilot report. J. Bodyw. Mov. Ther., 16:
7-13. Available from: http://www.ncbi.nlm.nih.gov/ pubmed/22196421

7. Lakes K.D., Hoyt W.T. (2004) Promoting self-regulation through school-based martial arts training. J. Appl. Dev. Psychol., 25: 283-302. Available from: https://www.sciencedirect.com/science/article/pii/S0193397304000309.

8. Lystad R.P. (2015) Injuries to Professional and Amateur Kickboxing Contestants: A 15-Year Retrospective Cohort Study. Orthop. J. Sport Med., 3: 2325967115612416 Available from: http://www.ncbi.nlm.nih.gov/ pubmed/26740949.

9. Lystad R.P., Strotmeyer S.J. (2018) Concussion knowledge, attitudes and reporting intention among adult competitive Muay Thai kickboxing athletes: a cross-sectional study. Inj. Epidemiol., 5.

10. McNoe B.M., Chalmers D.J. (2010) Injury in community-level soccer: development of an injury surveillance system. Am. J. Sports Med., 38: 2542-2551. Available from: http://www.ncbi.nlm.nih.gov/pubmed/20847226.

11. Orhan S., Yücel A., Sadeq B., Orhan E. (2019) Investigation of the Exercise Dependence of Athletes Doing Kickboxing, Taekwondo, and Muay Thai. Sports, 7: 52.

12. Ostrom C., Bair E., Maixner W., Dubner R., Fillingim R.B., Ohrbach R., Slade G.D., Greenspan J.D. (2017) Demographic Predictors of Pain Sensitivity: Results From the OPPERA Study. J. Pain, 18: 295-307. Available from: http://www.ncbi.nlm.nih.gov/pubmed/27884689.

13. Racine M., Tousignant-Laflamme Y., Kloda L.A., Dion D., Dupuis G., Choinière M. (2012) A systematic literature review of 10 years of research on sex/gender and experimental pain perception - Part 1: Are there really differences between women and men? Pain, 153: 602-618. Available from: http://www.ncbi.nlm.nih.gov/pubmed/22192712.

14. Rainey C.E. (2009) Determining the prevalence and assessing the severity of injuries in mixed martial arts athletes. N. Am. J. Sports Phys. Ther., 4: 190-199. Available from: http://www.ncbi.nlm.nih.gov/pubmed/21509103.

15. Romaine L.J., Davis S.E., Casebolt K., Harrison K.A. (2003) Incidence of injury in kickboxing participation. J. Strength Cond. Res., 17: 580-586. Available from: http://www.ncbi.nlm.nih.gov/pubmed/12930190.

16. Shimoyama T., Masuda I., Numa T., Horie N. (2009) Mandibular fracture with a mouth formed mouthguard in kickboxing. Dent. Traumatol., 25: 242-244. Available from: http://www.ncbi.nlm.nih.gov/pubmed/19290908.

17. Silva J.J.R., Del Vecchio F.B., Picanço L.M., Takito M.Y., Franchini E. (2011) Time-motion analysis in Muay-Thai and Kick-Boxing amateur matches. J. Hum. Sport Exerc., 6: 490-496.

18. Slimani M., Chaabene H., Miarka B., Franchini E., Chamari K., Cheour F. (2017) Kickboxing review: Anthropometric, psychophysiological and activity profiles and injury epidemiology. Biol. Sport, 34: 185-196. 
19. Vaseenon T., Intharasompan P., Wattanarojanaporn T., Theeraamphon N., Auephanviriyakul S., Phisitkul P. (2015) Foot and ankle problems in Muay Thai Kickboxers. J. Med. Assoc. Thail. 98(1): 65-70.

20. Zabel A.M., McGrew A.B. (1997) Ergonomics. A key component in a CTD control program. AAOHN J., 45: 350-358; quiz 359-360. Available from: http://www. ncbi.nlm.nih.gov/pubmed/9250029.

21. Zazryn T.R., Finch C.F., McCrory P. (2003) A 16 year study of injuries to professional kickboxers in the state of Victoria, Australia. Br. J. Sports Med., 37: 448-451. Available from: http://www.ncbi.nlm.nih.gov/ pubmed/14514540.
Received 30.01.2020
Accepted 05.04.2020

(C) University of Physical Education, Warsaw, Poland

Acknowledgments

GAFDwould like tothank CoordenaçãodeAperfeiçoamento de Pessoal de Nível Superior - Brazil (CAPES), finance code 001, for the scholarship concession. We would also like to thank Liga de Estudos em Fisioterapia Esportiva da UFRN (LEFERN) for academic support. 